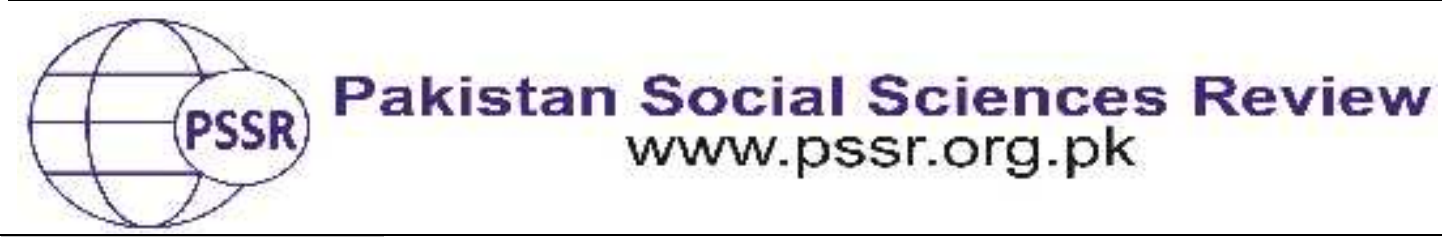

RESEARCH PAPER

\title{
Assessment of Learning or Assessment for Learning: A Case Study of STEP Sunday School for Working Children
}

\author{
Gouhar Pirzada ${ }^{1}$ Dr. Fariha Gul 2 Mahwish Mukhtar ${ }^{3}$
}

1. M. Phil Scholar, Department of Education, University of Management and Technology, Lahore, Punjab, Pakistan

2. Assistant Professor, Department of Education, University of Management and Technology, Lahore, Punjab, Pakistan

3. Lecturer, Department of English, Onaizah Colleges, Onaizah, Saudi Arabia

\begin{tabular}{|c|c|}
\hline 0 & \\
\hline $\begin{array}{l}2020 \\
2020\end{array}$ & $\begin{array}{l}\text { This paper helps in } \\
\text { assessment in a non-f } \\
\text { country like Pakistan, } \\
\text { formal education sect } \\
\text { education. After the d }\end{array}$ \\
\hline 1, & $\begin{array}{l}\text { 1mportant process of achieving possible lea } \\
\text { Mixed method approach was applied in collect } \\
\text { different administration, head of department, } j\end{array}$ \\
\hline 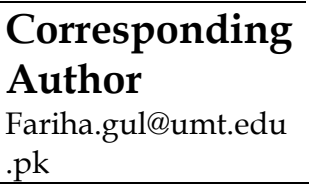 & it. \\
\hline
\end{tabular}

\section{Introduction}

This is the era of science and technology. Learning is considered mainly as the attainment of what the teacher or trainer desires to demonstrate and little devotion is rewarded to whether, or how, this knowledge might be modified in the process. The current predominant condition in a developing country like Pakistan proposes that non-formal educational institutions need to pay attention to the changing global trends of education. The development of a NFE policy 2019 is one of the initial steps for creating equal opportunities for NFE sector in the country.

In the field of education, assessment is an important process of achieving possible learning outcomes from students by assembling data. More precisely, it is the method through which trainers collect facts about their coaching and their 
students' learning. This research study discusses "Assessment for Learning" usually linked with 'Formative Assessment' and "Assessment of Learning", which is more connected with 'Summative Assessment'.

In 1998, Black and William's in their booklet "Inside the black box" advocated one of the most influential vehicles for urging teachers and officials, that assessment for learning (Formative Assessment) is beneficial for our students. However, the changing demographics, psychographic and advancement of technology have created a notably wider space for nonconventional school systems that can operate parallel to traditional formal school system. These wide ranges of educational initiatives enable lifelong learning or education where the former finds it challenging to operate.

Assessment is considered to be a precarious step in education process. Through it we can easily predict that whether the objective of learning has been accomplished or not. It affects many aspects related to education, consisting of student scores, assignment, and improvement as well as syllabus, instructional desires, and school finance etc. It is also taken as the process of gathering data. In modernized civilization, assessment is the technique of determining who will take the compensations of society (Ruland, 2011). Traditionally, assessments and evaluation both have been practiced to measure the accomplishment of pupils or institutions related with other pupils or institutions to place them in vigorous structure. In early 1850, schools in America were mostly 'a single room premises' and the prominent outcome of assessments in those times was hardly a grade. The usual assessment presentation resulted in a "pass" or "fail". The mid nineteen century did not witness any significant changes or improvements generally in the education systems and specifically in areas concerning students' performance and achievement standards. The general and most popular format of assessing students' learning achievements has been based on student's capabilities and time. The norm based assessment criteria has further elaborated the argument of getting useful results by comparing the performance of all students with other. Assessment would be practiced to categorize pupils and schools by how they executed their tasks when linked with other students (Ruland, 2011). The parallel argument of not binding the assessment of student's performance with age is a highly verbose, static and bureaucratic arrangement. Education was not systematized by age, but definitely by aptitude, accomplishment, and need for growth.

\section{Literature Review}

The main debate within primary education is the provision of educational assessments particularly in non-formal education sector. Educational Assessments are considered as a method to review the impact of feedback on learners in classrooms (Wiliam, 2011). It is a systematic process of collecting empirical data on knowledge, skills, and attitudes to improve the programs and refine student learning. Educators and researchers often focus on providing evidences on delivering effective education assessments but lesser research is available on non- 
formal education sector. The two assessments that are given importance in the field of education are 1) Formative Assessments (FA) and 2) Summative Assessments (SA). Firstly, FA is also known as assessment for learning is a way to improve student's performance by taking information for the learning processes that teachers can use for instructional decision (Wiliam, 2011). However, FA is considered as an assessment for learning practice as it provides feedback and information to students, teachers, and educational stakeholders about the learning process during the instructions. Secondly, SA or assessment of learning is defined as the evaluation of student's academic performance at the end of the specified time period (i.e. an entire school year) for establishing a student's academic understanding according to the assigned course. Therefore, it is also considered as an assessment of learning method to examine the students after the instructions are delivered completely.

This research creates an impact by emphasizing these concepts in NFE sector which do not exist in the literature. It is vital to emphasize that non-formal education is not only meant for physical or mental specially-able learners. Instead the stigma associated with non-formal education needs to be amplified as an alternative to regular teaching scenarios, methodologies and assessments, where it is applicable, and not merely as a substitute. The discussion and investigation on assessment becomes even more important in the context of Pakistan. Being the $5^{\text {th }}$ populous country, with scarce resources and comparatively lesser priority towards literacy and education, there requires an objective discussion and research to analyze the appropriateness of assessment techniques in the non-formal education of country.

The variables being used in this research study as sub factors of effective teaching include "Teacher's Competencies (TC)" (Spreitzer), "Student's Learning Achievement (SLA)" and "Teacher's Self-Efficacy (TSE)" in which;

Teacher's Competencies (TC) refers to all those characteristics related to teachers that help in producing encouraging educational outcomes. These may include but not limited to cognitive characteristics and professional specific knowledge of teachers (Kunter, 2013).

Student's Learning Achievement (SLA) demonstrates the characteristics of modeling (demonstrating) quality, giving feedback, self-assessment, student's domain specific learning and motivation (Kunter, 2013).

Teacher's Self-Efficacy (TSE) is considered in a way in which teacher interpret and integrate information to make their abilities for achieving student's success. For this research TSE includes perceived self- efficacy in class room and demographic \& psychographic understanding about students (Mohamadi, 2012). 


\section{Hypotheses}

1. Effective teaching has a significant positive relationship with Formative Assessments

2. Effective teaching has a significant positive relationship with Summative Assessments

\section{Conceptual Framework}

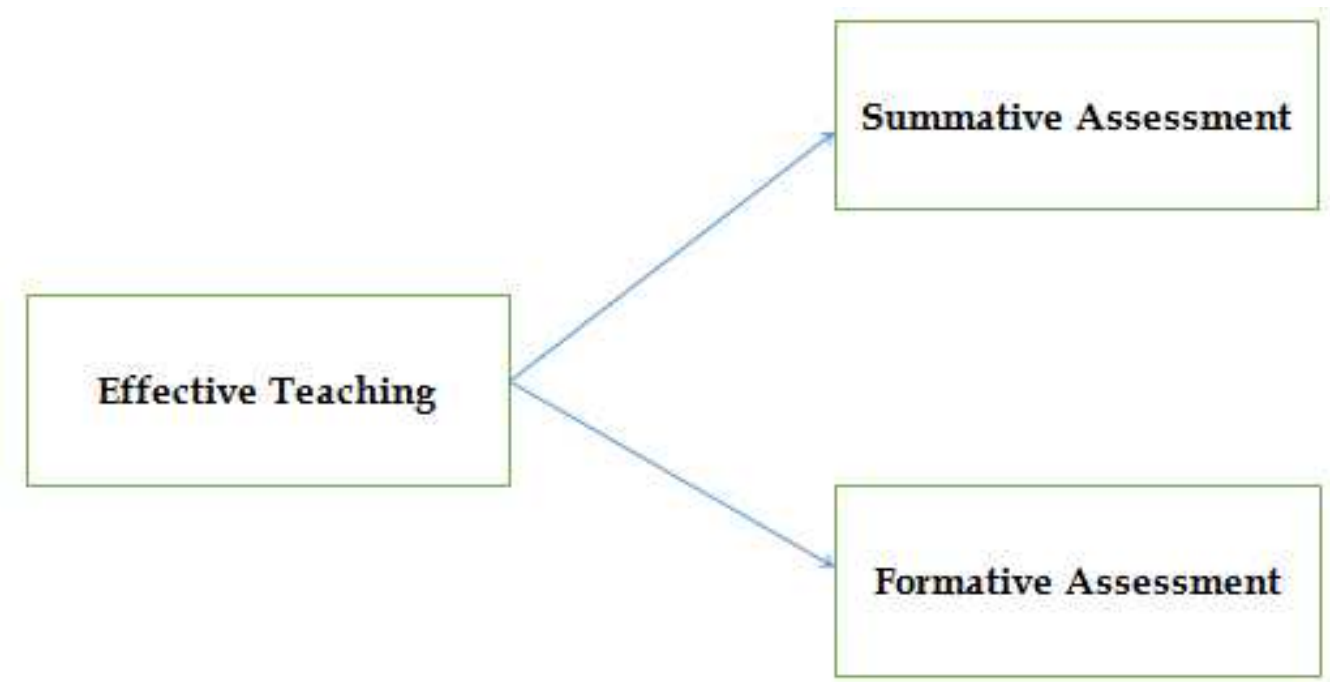

Effective teaching includes;

- $\quad$ Teacher's Competencies (TC)

- Student's Learning Achievement (SLA)

- Teacher's Self-Efficacy (TSE)

\section{Material and Methods}

Quantiative research methodology as applied in investigating the research objective. The instrument of quantitative analysis was created according to the elements or sub-factors which directly or indirectly are related to FAs and SAsstrategies. The populations for the quantitative approach include head of departments, senior and junior teachers employed in NFE sector across the country. Convenience and purposive sampling was used as a samplling technique for this research. 


\section{Population/Sample Size}

Participants in this study were 213 who work in different NFE institutes of the country. The responses were collected from both genders lying between the professional working experiences of more than one year. This population is considered as the most relevant in discussing the best assessment method in NFE sector. The data also includes the names of training institutes with the respondents have training acquired of more than 6 months.

\section{Research Design}

Cross-sectional study design is used for this study that is a type of observational study design to compare and recommend the outcome from both types of asssessment methods in NFE sector. The research design has also assist to assess the comparative impact of different issues NFE sector.

\section{Pilot Study}

Pilot study for this research includes 25 questionnaires from the staff members of Sunday school project in STEP. The pilot study helps in accessing the feasibility of the project and also ensures the reliability of the instrument. This pilot study helps to gather information prior to a larger study in order to improve the quality of the final study.

\section{Qualitative}

Total nine interviews were conducted to discuss the challenges of non-formal education sector in terms of adopting two different assessment techniques. The participants included teachers and administrative staff working in a non-formal education institute across the city. The selected participants were directly engaged with the students in the process of adopting both types of assessment techniques. The qualitative research methodology allow researcher to collect insights of the research phenomena from respondents views. The flexible nature of the interview based methodology help researcher to interpret the participant's viewpoints.

\section{Results and Discussion}

\section{Respondent's Profile}

Demographic results obtained by running frequency tests on the data set that includes more number of females (69.3 percent) than males (30.7 percent), higher number of respondents were having a bachelors (16 years) degree than others, the majority of our respondents lies between the age of 25-30 years (55.2 percent combine) and the maximum respondents were senior teachers from non-formal education sector (43.9 percent). Furthermore, maximum respondents acquired training of less than 6 months (32.1 percent). The total results for demographic characteristics of each variable with percentages can be analyzed from table 1 . 
Table 1

Demographic Characteristics

\begin{tabular}{cc}
\hline Variables & Percentages (\%) \\
\hline Gender: & 100 \\
Male & 30.7 \\
Female & 69.3 \\
\hline Education: & 100 \\
Bachelors 14 years & 20.3 \\
Bachelors 16 years & 31.1 \\
Post graduate & 18.4 \\
B. Ed & 4.2 \\
M. Ed & 5.7 \\
Other & 20.3 \\
\hline Age (in years): & 100 \\
Less than 25 & 24.1 \\
25-30 & 55.2 \\
36-45 & 16 \\
Greater than 45 & 4.7 \\
\hline Employment Level & 100 \\
HOD & 15.6 \\
Senior Teacher & 43.9 \\
Junior Teacher & 40.6 \\
\hline Training Acquired & 100 \\
Less than 6 months & 32.1 \\
6 months-1 years & 26.4 \\
1-2 years & 16.5 \\
More than 2 years & 17.9 \\
Other & 7.1 \\
\hline
\end{tabular}

\section{Reliability Tests}

Self-administered survey questionnaire were adopted from other study. The internal consistency was check and reliability analysis was run using the Cronbach's Alpha, which was 0.990 for complete questionnaire. The reliability analysis was run on each variable separately and the values of Cronbach's Alpha of effective teaching have .980 , formative assessments have .978 , and summative assessments have .946 . The Cronbach's Alpha values of all variables were greater than .9 that shows that the internal consistency of the variables is reliable.

Table 2

Reliability Tests

\begin{tabular}{ccc}
\hline Variable & No of items & Cronbach's Alpha \\
\hline Effective teaching & 6 & .980 \\
\hline Formative Assessments & 13 & .978 \\
\hline Summative Assessments & 10 & .946 \\
\hline & 1031 &
\end{tabular}


After establishing reliability, the variables were furthered tested with ANOVA for analyzing the difference among group means in the sample. For our first hypothesis, the $\mathrm{p}$ value is less than 5\% among GT and FA that shows the significant relationship between both variables and thus accepting our first hypothesis. Similarly, the p value among GT and SA is also less than $5 \%$ that shows the significant relationship between them and thus accepting our second hypothesis.

Table 3

Mean difference between scores of perceived level of assessment

\begin{tabular}{cccccc}
\hline Variables & Mean & SD & Df & F-value & Sig. \\
\hline AvgFA & 5.540 & 1.28649 & 211 & 49.645 & .000 \\
\hline AvgSA & 3.738 & 1.09692 & 151 & 19.074 & .000 \\
\hline AvgGT & 6.615 & 1.25278 & 211 & 79.040 & .000 \\
\hline
\end{tabular}

\section{Qualitative Data Analysis}

The qualitative analysis of the data provides some important insights on the research topic. Mostly respondents agreed that they have enough skills to conduct summative assessments. While six out of nine respondents realized that they likely get enough time and have enough skills to conduct summative assessments. Whereas, mostly respondents accepted that they always encourage students in nonformal sector to ask questions. Encouraging such under privileged class will help them to think about themselves as an important part of the society. While on the other side, formative assessments is also considered necessary as they find such assessments important to identify students and weaknesses. Nevertheless, both types of assessments techniques are considered important for students learning, growth, and development in Non-formal education sector. The following graphs show 19 important factors that were emerged from the qualitative data. These factors were highlighted by the respondents while conducting summative and formative assessments in a non-formal education sector.

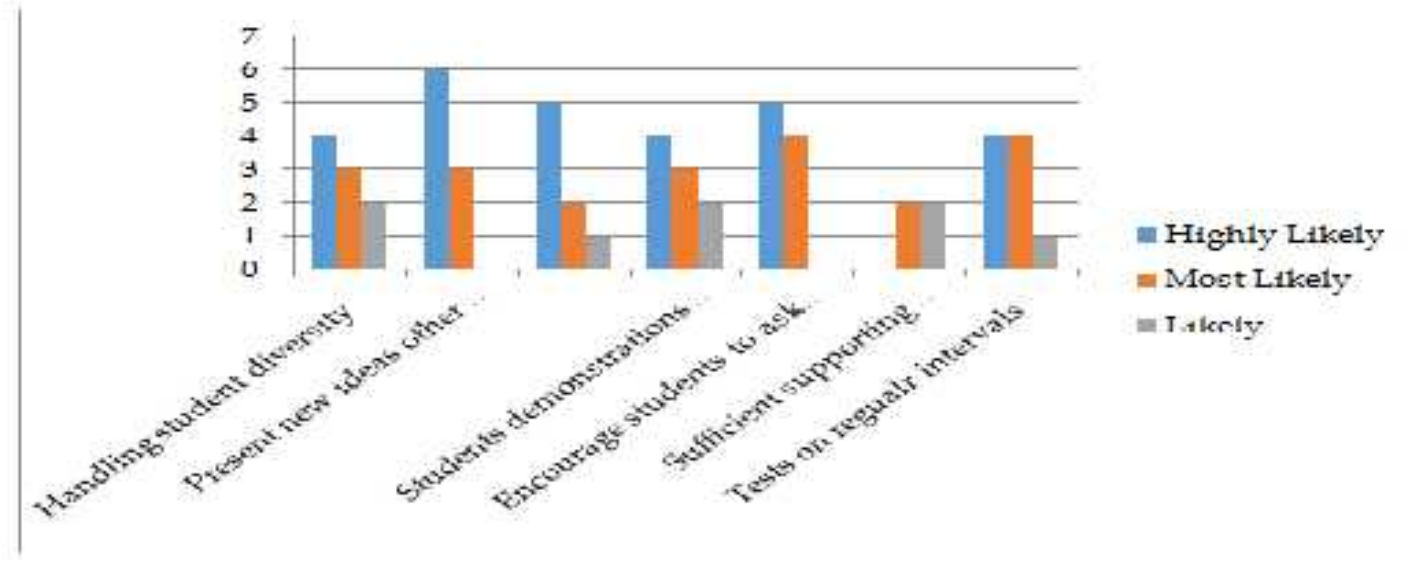




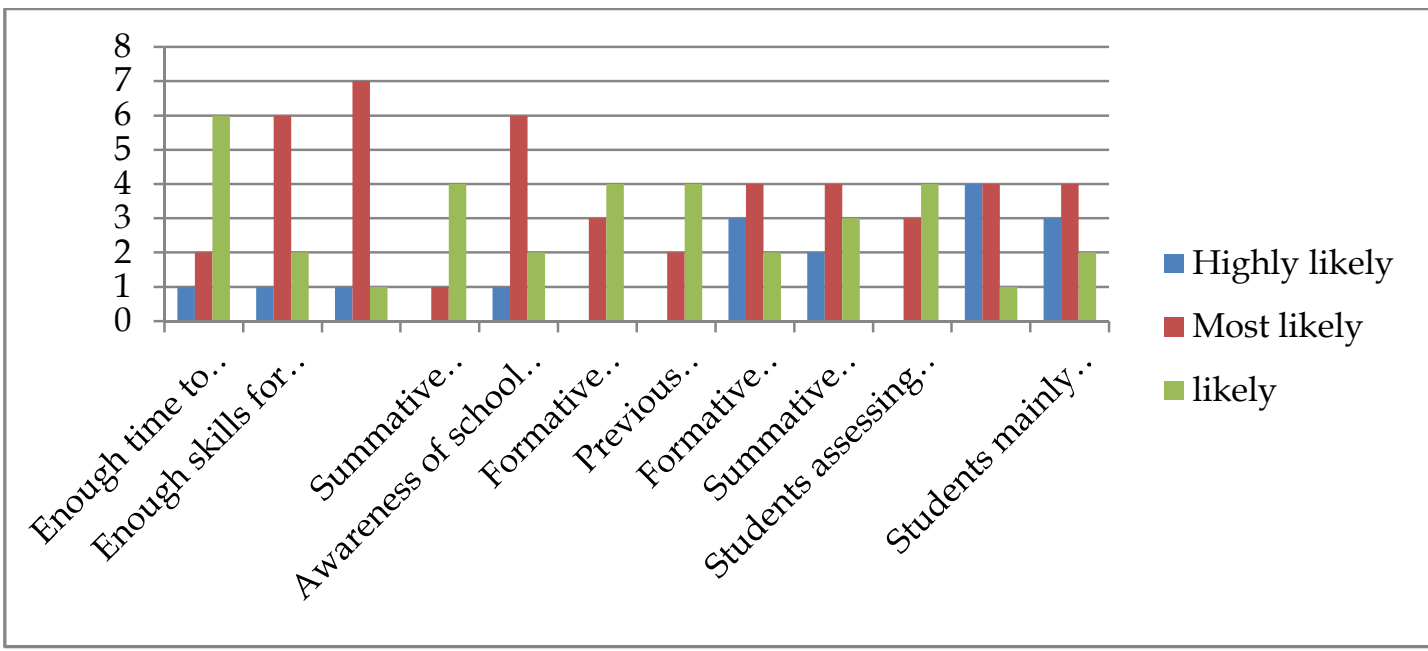

The graphs below shows the preferable assessment techniques used while teaching in a non-formal education environment. It can be analyzed that the technique of oral question and answer were mostly preferred by the respondents as it encourage the students to develop their interest in the studies.

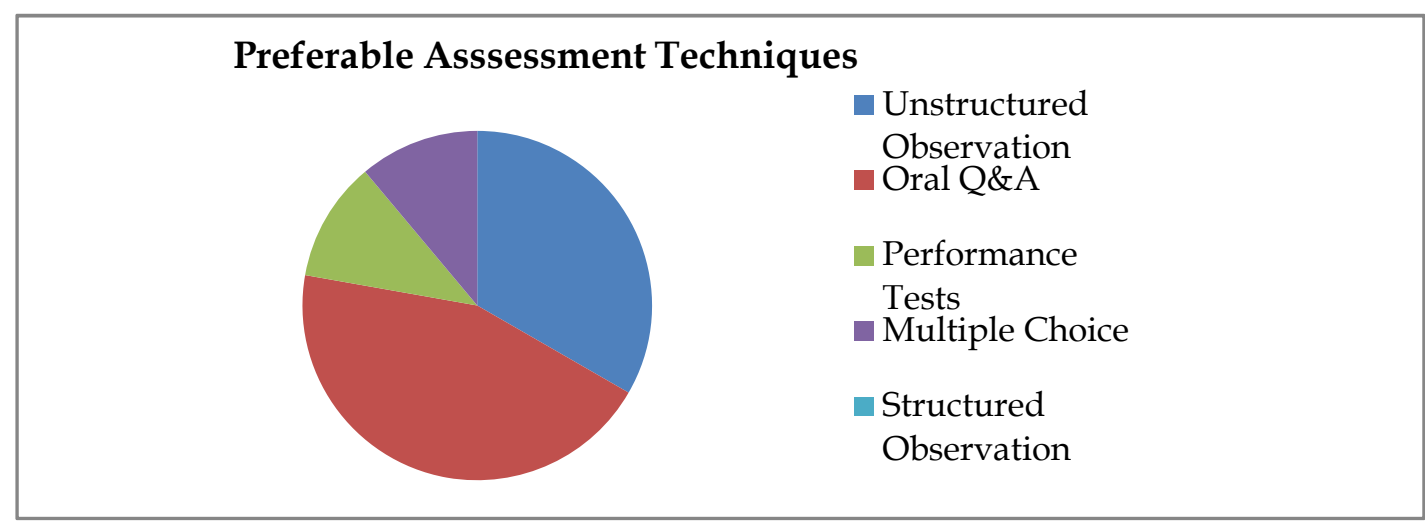

The graph below shows the analysis of different techniques that are applied in a non-formal education sector. In the context of applying different assessment techniques, most participants used classroom observation as most frequently used assessment technique. Other than classroom observation, oral questioning was also given importance for conducting assessments in a non-formal education environment. 


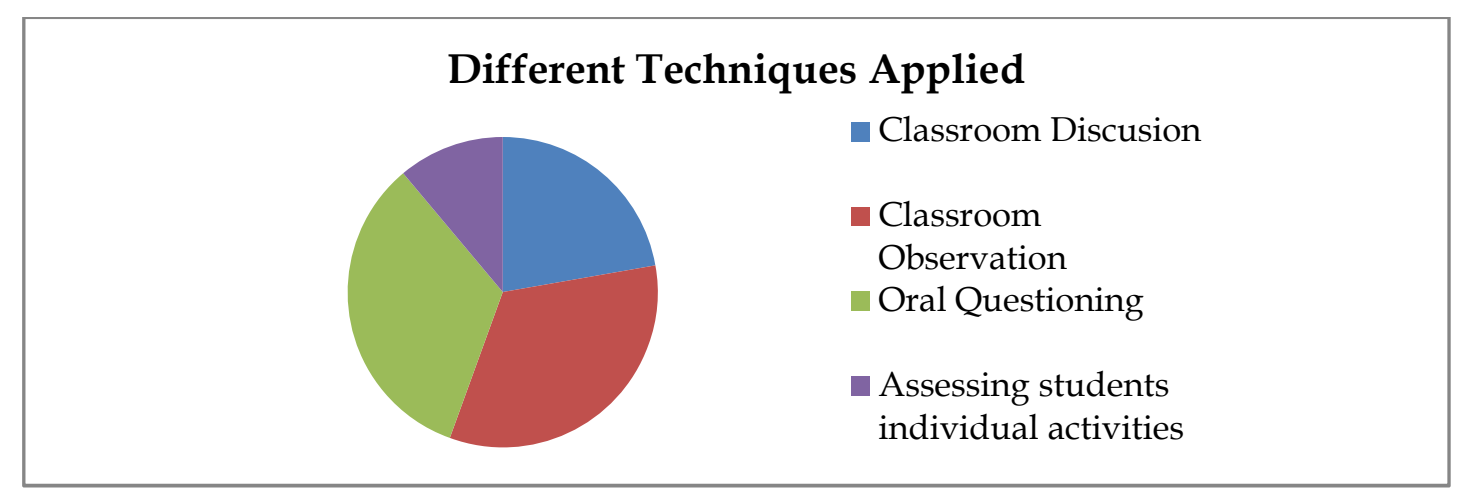

\section{Discussion}

There is a large need to spend more money on strengthening the NFE system and operations in Pakistan. The results of this study reveal that the both type of assessments are equally important in non-formal education sector of Pakistan. Since, student's learning achievement and teacher's strong self-efficacy are concentrated to one another, it is important to examine the factors that could increase the sense of efficacy in teachers. In this study, assessment for learning and assessment of learning both are considered crucial for achieving student's orientation in the less privileged class of students that belong to non-formal sector. The findings of this study support the previous literature that demonstrates the strong effect of assessments on student's learning.

In addition, this study was the first attempt to examine the effective teaching behavior in relation with formative and summative assessments in NFE sector. Since, vast study of literature in the field belongs from the developed nations and there is insufficient knowledge and information is presented in the context of developing countries. Much more attention needs to be given in the field for increasing the efficacy of teachers in NFE sector.

\section{Conclusion}

The comparison between both types of assessments move towards additional empirical attention through both qualitative and quantitative research methodologies. In addition, this cross contrast evaluation of both types of assessments seek to determine how these relationships might vary in formal education sector characteristics or as a function of the interrelation of contextual variables. Nevertheless, our study goes beyond the traditional arguments by studying both type of assessments for a better teaching experience and students learning in a different educational environment. 


\section{References}

Bjørnåvold, J. (2000). Making Learning Visible: Identification, Assessment and Recognition of Non-Formal Learning in Europe, CEDEFOP http://www.oecd.org/education/skills-beyond-school/41834711.pdf

Brown, E. J. (2018). Practitioner perspectives on learning for social change through non-formal global citizenship education. Education, Citizenship and Social Justice, 13(1), 81-97.

Carr, A. Balasubramanian, K. Atieno, R. \& Onyango, J. (2018). Lifelong learning to empowerment: beyond formal education. Distance Education, 39(1), 69-86.

Duvekot, R. (2001). The dynamics of non-formal learning and the opening-up of national learning systems. Lifelong learning: Which ways forward?, 58.

Egbezor, D. E. \&Okanezi, B. (2008). Non-formal education as a tool to human resource development: An assessment. International journal of scientific research in education, 1(1), 26-40.

Empson, L. (2015). Leadership, Power, and Politics in Law Firms. In: R. NormandHochman \& H. Gardner (Eds.), Leadership for Lawyers. (pp. 89-102). Globe Law and Business in association with the International Bar Association. ISBN 9781909416789

Latchem, C. (2018). Open and Distance Non-formal Education Open and Distance Non-formal Education in Developing Countries (pp. 11-17): Springer.

Mohamadi, F. S. \&Asadzadeh, H. (2012). Testing the mediating role of teachers' selfefficacy beliefs in the relationship between sources of efficacy information and students achievement. Asia Pacific Education Review, 13(3), 427-433.

Ololube, N. P. \&Egbezor, D. E. (2012). A critical assessment of the role/importance of non-formal education to human and national development in Nigeria: future trends. International journal of scientific research in education, 5(2), 71-93.

Rogers, A. (2007). Non-formal education: Flexible schooling or participatory education? (Vol. 15): Springer Science \& Business Media.

Rogers, A. (2019). Second-generation non-formal education and the sustainable development goals: operationalising the SDGs through community learning centres. International Journal of Lifelong Education, 38(5), 515-526.

Rogers, A. (2019). Second-generation non-formal education and the sustainable development goals: operationalising the SDGs through community learning centres. International Journal of Lifelong Education, 38(5), 515-526. 
Ruland, J. W. (2011). The impact of using formative assessment attributes in daily instruction on student affect. Loyola University Chicago.

Sufyan, A. Nurhalim, K. \& Shofwan, I. (2019). Learning Management of Nonformal Education units in SanggarKegiatanbelajar. Journal Of Nonformal Education, 5(1), 57-66.

Wiliam, D. (2011). What is assessment for learning? Studies in educational evaluation, $37(1), 3-14$.

Yiu, L. \& Saner, R. (2009). Assessment and Accreditation of Non-Formal Management Education and Development Programmes. The SAGE Handbook of Management Learning, Education and Development, London: SAGE Publications, doi, 10(9780857021038), n28. 